\title{
An overview of the cognitive and biological effects of city nighttime illumination including a London case study
}

\author{
Dr. Karolina M. Zielinska-Dabkowska ${ }^{a}$, Kyra Xaviab ${ }^{b}$ \\ a GUT Light Lab, Gdańsk University of Technology (GUT) \\ b Dunedin Dark Skies Group
}

\section{Introduction: What do we know?}

Current scientific research demonstrates how critical the effects of city nighttime illumination are upon cognitive and biological health ${ }^{1}-$ which needs to be adequately acknowledged, understood and addressed by conscious cities and the plans they develop. Until recent decades, the design of nighttime lighting was determined mostly by electrical engineers who often applied technical standards to meet the requirements of vehicle-focused cities. Unfortunately, consideration of pedestrians and their visual needs to navigate

throughout urbanscapes at night were ignored, and so too, was the impact that artificial lighting might have on them, and the environment. Today, the majority of urban city lighting has been installed without full awareness of its impact, and as a result, artificial light at night (ALAN) and light pollution have become an obvious public nuisance, a health risk and an environmental burden ${ }^{2,3}$. While poor lighting has its drawbacks, a lack of lighting can have many positive aspects, and urban settings can benefit from protecting, preserving and promoting natural darkness. We present two recent planning and design initiatives of London, in the UK, where the quality of light and value of darkness were not given the degree of attention and consideration they deserve. This paper has particular relevance for urban policy makers, city planners, architects, designers, consultants and researchers as it explores the various problems caused by the obvious lack of responsible nighttime illumination.
Today, climate change, environmental pollution and health are all considered important issues that need due attention by international organisations, governments and initiatives ${ }^{4-5}$.Yet, one of the most crucial, but often neglected issues to address is properly and carefully designed nighttime illumination that takes into account its cognitive and biological effects. The vast majority of urban lighting at night escapes any kind of guidance and control until it becomes an obvious public nuisance or a recognised problem. This is particularly relevant because our cities now operate $24 / 7$, and the more we light up our environment, the more mindful we need to be of the consequences of doing so.

For a city or town to truly thrive, decision-makers must better understand the impact of light at night - and how fundamental it is to use light in built and natural environments with care and caution. Intelligent lighting is well designed, thoughtfully placed, and implemented correctly to minimise adverse biological impact, yet maximise its effectiveness. Such lighting performs its task while being pleasant to be around and complementary to its surroundings. Most importantly, it is also human-centric, nature-kind, and night sky-friendly.

Not only does this kind of high-benefit lighting substantially enhance art and culture, heritage, and the appearance and atmosphere of a city, it boosts the economy, tourism, and the use of public spaces, whilst crucially, also supporting biodiversity, health and wellbeing, and the life quality of residents/visitors. In fact, all of the above demonstrates how paramount it is to prioritise responsible, sensitive, carefully designed illumination.

\section{Shaping the city's nighttime legibility - cognitive effects}

Cognition has been investigated from many perspectives but such study has mainly been limited to daylight hours. In 1948, psychologist Edward Tolman introduced the concept of cognitive maps which explored how humans gather and process information about their location and the specific features of three-dimensional settings ${ }^{6}$. Then 12 years later, in 1960, Kevin Lynch developed and adopted a model, explained in the book "The image of the city," which defined the essential elements of urban planning that affect how a city is perceived during the day ${ }^{7}$. His "mental map" was a generalized picture of the external physical world which makes the environment familiar and easy to navigate. According to Lynch, "Nothing is experienced by itself, but always in relation to its surrounding"8. 
The change in the way we now understand a city was initiated by Lynch's model which turned out to be the key to today's concept of city nighttime illumination, with the composition of lit urban elements such as edges, paths, nodes, landmarks and districts interlinked with each other by means of light.

In regard to the topic of this paper, we understand cognition as the conscious and unconscious processes by which knowledge is accumulated. This involves perceiving, recognising, conceiving, and reasoning ${ }^{9}$ while performing the act of navigation through a three-dimensional space at night.

How effectively we navigate our surrounding hinges on visual input. Our ancestors were active during the day and they evolved photopic vision in bright daylight conditions to perform necessary tasks. As scotopic (nighttime) vision was not required, the ability to see well in the dark was not developed by humans ${ }^{10}$.

Fast forward to modern times, where we have extended our days into the night with artificial light to continue activities. Lighting for legibility in cities and towns has become the norm in order to function and navigate, especially for work and leisure, but due to a lack of awareness and unutilised expertise, urban lighting is most often excessive, when less lighting, that is also applied skilfully, could achieve superior results.

While we need to feel safe, secure and comfortable in the urban environment after dark, bright light and overlighting only provides the illusion of safety. In reality, such lighting impairs visibility (glare can temporarily blind us ${ }^{11}$ so we instinctively look away from a bright light source, shield or squint our eyes), it decreases the ability to recognise objects (preventing dark adaptation so it takes time to adjust to different lighting levels ${ }^{12}$ ), it compromises safety (strong contrast restricts the pupil in the eye and hinders the ability to detect objects in shadows and perceive possible threats or hazards ${ }^{13}$ ), and it also reduces visual comfort. The legibility of a space is particularly important after dark as it aids understanding, which in turn, reduces feelings of disorientation and unease. (Unease greatly contributes to the perception that a space may be unsafe.)

From a psychological perspective, a person needs to understand the three-dimensional space they are in and they must also be able to perceive any potential danger (be it a human, animal or an object) at a distance or close up. This is one of the reasons why the illumination of vertical surfaces at the perimeter level (close views) and at the higher level (mid and distance views) is necessary when navigating the cityscape at night.

Artificial lighting that reveals the form and surfaces of a city's buildings and structures, can assist with finding our way by highlighting specific architectural objects and reference points (landmarks) that stand out in the urban space on the way to a desired direction. Additionally, research shows that human vision will always be directed and attracted to the brightest point in the field of view ${ }^{14}$ so establishing the right contrast ratio between an object and its surrounds is of utmost importance for visual comfort.

Quality lighting takes into account our physiology. 1.8 million years ago, when Homo erectus, known as the "upright man" evolved, humans as a species acquired forward looking vision (Figure 1). Even though forward looking vision functions much more effectively with vertical illumination, most cities today use horizontal illumination. Pedestrian routes in particular, should be illuminated differently to the way streets are lit for vehicles. The only areas that require appropriate levels of horizontal illuminance and notable contrast are steps, stairs and curbs, due to the fall and trip hazard, especially for older adults. 


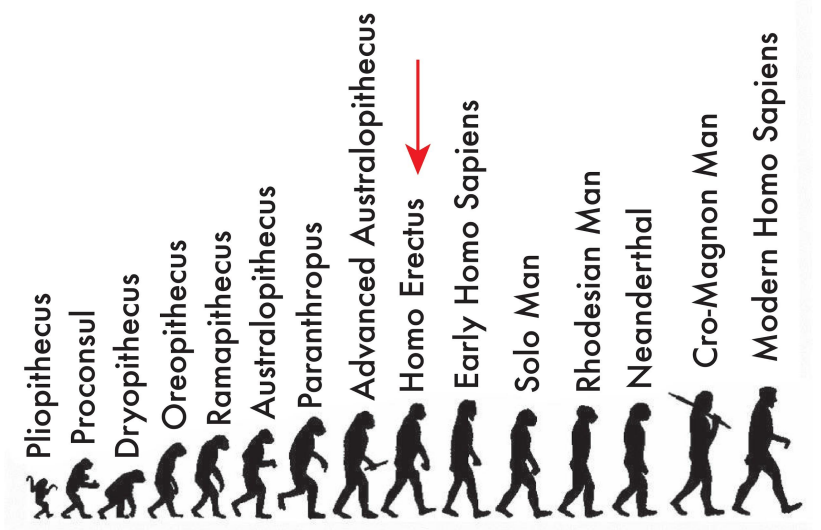

Fig.1. Homo erectus with forward looking vision. ( K. M. Zielinska-Dabkowska.

The way our surroundings are lit helps determine how we perceive and experience that space. It also influences behaviour within that space and how it is used. (Recent research confirms that in order to guide navigation in the dark and to support the development of a cognitive map, visual and idiothetic motion cues are necessary ${ }^{15}$ ). This means the cognitive impact of lighting requires just as much consideration as do the biological effects.

Public spaces can be beautifully and creatively illuminated to evoke a sense of comfort so people enjoy and appreciate them, all without compromising health, legibility, safety and security - and this is the kind of lighting that needs to be encouraged, promoted and valued.

\section{City's nighttime illumination - biological effects}

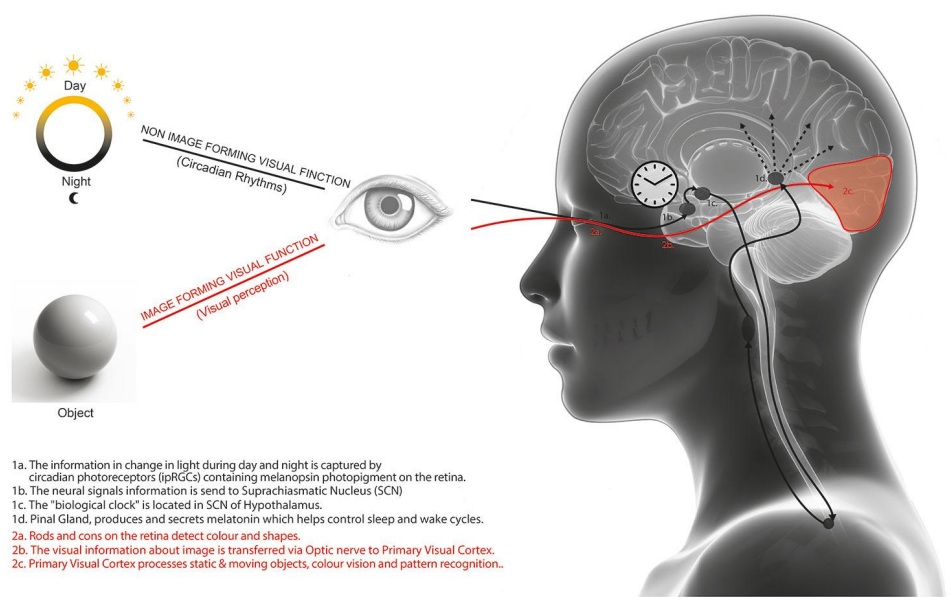

Fig.2. Light that reaches the human eye has visual and non-visual effects - with the latter influencing our biological clock. () K. M. Zielinska-Dabkowska and V. Labancova

Light, be it natural or artificial, has visual and also biological effects (Figure 2). Thus manmade lighting must be carefully deployed, ideally, with the guidance of professionals (lighting designers) who understand its impact and have expertise in its application.

For conscious cities, the biological effects of artificial light at night (ALAN) on living organisms must not be underestimated as the consequences are far reaching and broad-ranging. Exposure to ALAN, and also a resulting lack of sleep, are linked to wide range of illnesses, while sleep deprivation itself, is a recognised health problem that costs the economy billions of dollars in illness and lost productivity every year ${ }^{16}$ 
Light is known to affect human chronobiology more than any drug on the market. Our biological clocks, set by light, are responsible for much more than just sleep and wakefulness. They influence the most basic of metabolic pathways, the release of hormones, and regulate the daily rhythm of almost every system in the human body. In fact, the science involved in understanding the circadian clock was considered so important, in 2017, researchers were awarded the Nobel Prize ${ }^{17}$.

Furthermore, we're now dependent upon LED technology, using more of it than we ever have before, and the most energy-efficient LED light sources with a colour temperature of $4000 \mathrm{Kelvin}(\mathrm{K})$ and above, happen to be the most disruptive to the biological clocks of humans. Such lights have a spectral power distribution (SPD) with a peak in short-wave blue light part of the spectrum that tricks the body into thinking it is daytime at night ${ }^{18}$. This has serious ramifications because we evolved with a light/dark cycle and without adequate darkness at night, certain vital processes upon which health depends, cannot occur. Lighting up our nights as brightly as if they were days ultimately harms health, and even in the largest, most developed cities, we must use light with discretion whilst also understanding what SPD is best.

The same cellular sensitivity to light doesn't just apply to humans, but to most other living organisms as well, with countless scientific studies demonstrating the detrimental effect of ALAN upon different species from bats, birds, reptiles, fish, insects, plants and marine microorganisms like plankton and algae ${ }^{19}$.

As we know, biodiversity is key to a thriving ecosystem and a flourishing city, and human residents in built up settings, greatly benefit from being able to access nature in parks, reserves and waterways. For these reasons, nighttime illumination in cities needs to respect the requirements of flora and fauna, including the marine life in waterways. (This is especially important with the illumination of bridges, their walkways and cycle paths ${ }^{20}$ ).

Now that we're aware of the above consequences of artificial lighting at night (ALAN), and the impact of lights with an unsuitable SPD - lighting for visual appeal and the sake of entertainment alone is untenable. Lighting and special illumination effects must first and foremost be safe, as benign as possible to the environment (including ecology and the night sky), and supportive to the health and wellbeing of residents, flora and fauna.

\section{Preserving Darkness}

The invention of artificial lighting towards the end of the 19th century has seen the slow but steady erasure of darkness from our cities, and along with it, respect and appreciation for the important role it plays in our lives. Instead, a negative association developed that stemmed in part, from our basic human need to survive and a psychological fear of crime. Although research indicates improved lighting at night can help to reduce the fear of crime and increase the feeling of safety about being out after dark, (this tends to vary according to age and sex) - improved lighting does NOT reduce crime itself ${ }^{21}$. Offenders need light at night, not darkness, and they will use it to their advantage to scan for opportunities, seek out desired objects, target victims, and see what they are doing, all while being less conspicuous and able to blend in to the environment. (A more effective crime deterrent is motion activated sensors that turn lights on suddenly in zones that are normally dark at night, to show there is activity in an area where there shouldn't be.)

The unfortunate loss of darkness is a direct consequence of poor lighting practices, light pollution and skyglow - and the fallout of this has resulted in widespread environmental issues which have increased dramatically in recent decades ${ }^{22}$. In most large cities, people are unable to see the stars and planets with the naked eye, and they are also denied a view of the Milky Way. Under a night sky free of light pollution, about 2,500 individual stars are detectable, but less than a dozen can be observed in a typical city in a developed country. 
Every human being benefits from connecting with nature, and each one of us has the right to look up and to admire a starry night and experience the awe-inspiring wonderment of the Universe - the same resplendent firmament that our ancestors appreciated in the past. (In 2007, participants in the International Conference in Defence of the Quality of the Night Sky and the Right to Observe the Stars, in La Palma, Canary Islands, jointly with the representatives of UNESCO, UNWTO, IAU, UNEP-CMS, COE, SCBD, MaB, EC and Ramsar Convention, established the Starlight Declaration which affirms the inalienable human right to starlight and defines the night sky as a common and universal heritage and an integral part of the environment perceived by humankind ${ }^{23}$ ).

Nighttime aerial images of prosperous residential areas of any larger city, be it London, Paris or Berlin, reveal that these areas are much darker compared to the rest of the city, with significantly less sky glow and no light trespass. Interestingly, one can claim there is a social divide between economical classes between the rich who can afford to live in prime neighbourhood's locations, often near dark city parks, and the rest of society. In today's world, darkness and starry nights turn out to be a privilege of the wealthy.

A conscious city understands the need for preserving the darkness, implementing nocturnal placemaking, access to natural settings, and cultivating respect for the night for all citizens, without any division between sex, age or social classes.

\section{The unrealised potential of two London initiatives}

This paper discusses two recent initiatives where the quality of nighttime illumination and value of darkness were not given enough consideration: the draft New London Plan $^{24}$, and the 2016 Illuminated River International Design Competition, organised by the llluminated River Foundation ${ }^{25}$. This is especially surprising as London is home to the largest number of independent lighting practices in Europe, the head offices of the UK Chapter of International Association of Lighting Designers (IALD), the Institution of Lighting Professionals (ILP), and the Society of Light and Lighting (SLL) etc., with accessible expertise available to consult on appropriate nighttime lighting.

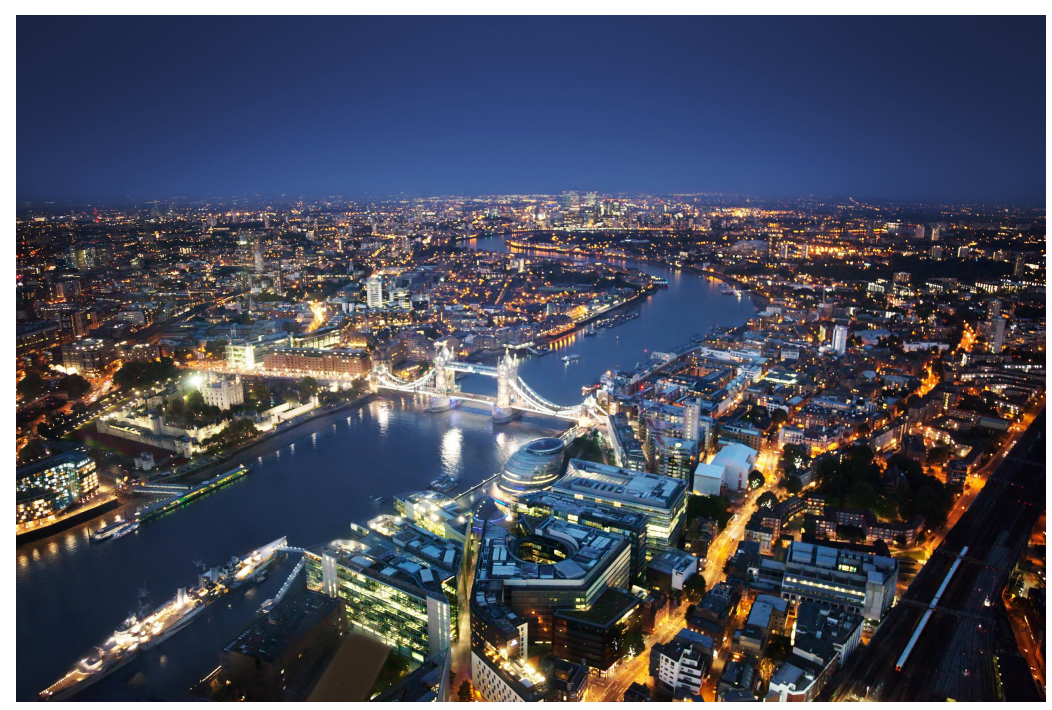

Fig.3. City of London. A coherent strategy that addresses nightime illumination in the city will provide countless benefits and advantages. @shutterstock/ lakov Kalinin 
The draft London Plan is a special development strategy created for the next quarter of a century by the Mayor of London and his office, and it serves as a blueprint for the future development and sustainable, inclusive growth of the London city (Figure 3). In this document, which was available for public consultations between 1st December 2017 and 2nd March 2018, artificial lighting and its impact have been marginally reflected upon ${ }^{26}$.

This is not a strategic approach by any means, and many other factors and aspects of lighting should be included and adequately explained. Only vague suggestions have been made about safety, security, energy savings and the avoidance of light pollution in regards to the public realm, outdoor sports and recreational facilities, and tall buildings. There are no detailed, specific recommendations on how to reduce the impact of artificial lighting on humans, flora and fauna - and there is also no information on other important elements such as urban lighting masterplan(s), Environmental Zones, LED lighting and lighting controls, and references to guidelines and good practice in this area. An explanation of "appropriate lighting", "external lighting", "light pollution" seems to be also missing.

Few lighting professionals were consulted about the lack of proper attention for the city's night time illumination strategy. Nor was there direct online consultation, mention of published articles, or an attempt to address and converse with a wider audience via comments on social media platforms (Linkedln). Unfortunately, all the requests and comments for detailed information and guidance appears not to be included in the revised draft document ${ }^{27}$. There is a visible need for policy recommendations of environmental impacts related to outdoor artificial lighting which requires consideration during planning applications. These should include, but are not limited to, the impact on fish and other species in the river Thames (due to illumination of bridges and river walls), the impact on city and migrating birds (due to the external and internal illumination of tall buildings disrupting their flight lines), the impact of light pollution on residents, recommendations made on appropriate colour temperature of the LED light sources, the reduction of flicker, and more.

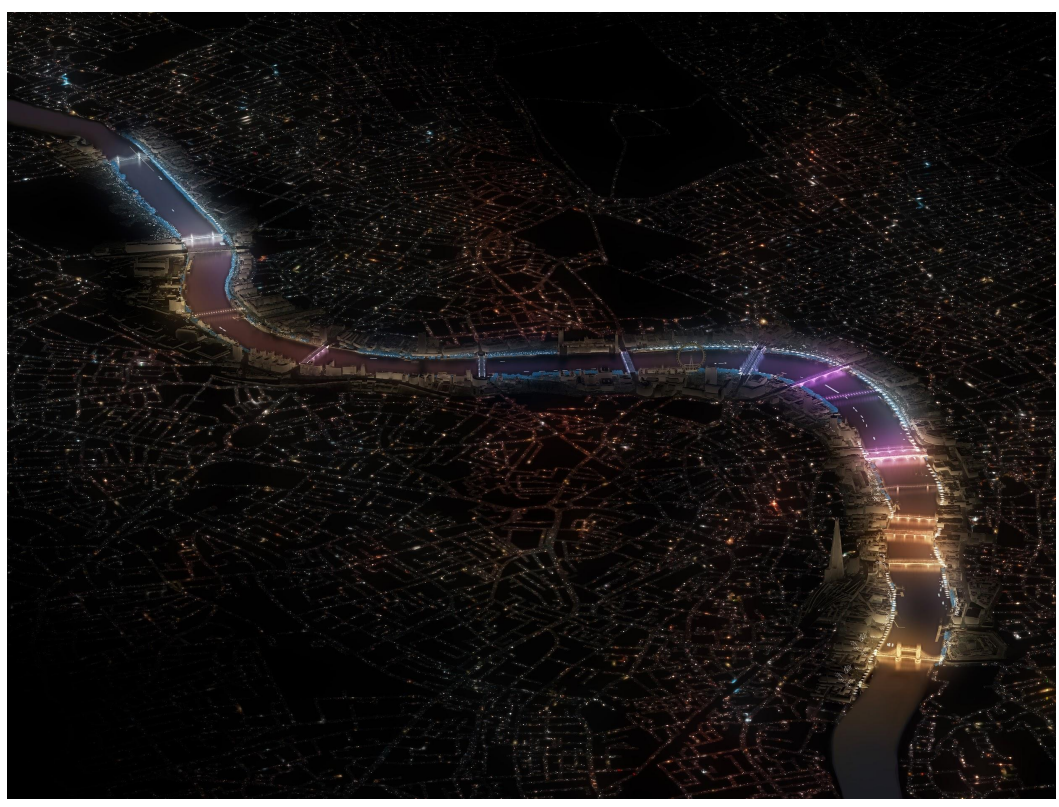

Fig.4. Winning entry of the Illuminated River International Design Competition in London. Although the proposal discusses energy performance, it does not mention the impact such lighting will have upon the environment, flora and fauna, and the river itself. @ Illuminated River Foundation 
The brief for the 2016 Illuminated River International Design Competition, which involves the illumination of 17 London bridges - made it a technical priority to "address and respect the diverse natural environment and wildlife habitats in the river generally, and the bridges specifically". However, the result will still be a tremendous increase in light pollution along the river that will negatively impact the marine environment and the night sky. The winning proposal called "Current" is typical of what we would see at a temporary light art festival, using a substantial amount of coloured kinetic lighting, however this will be a permanent installation (Figure 4). It will draw excess attention from the surrounding environment, and the use of blue light for illumination of the bridges will be detrimental to the local fish population, especially migrating salmon ${ }^{28}$.

Nighttime lighting must take into account local flora and fauna. Detailed and thorough consultations with biologists, biodiversity consultants, and environmentalists are necessary. Designers must consider the behavioural, cognitive and physiological effects of their work on both people and nature. For example, steps should be taken to reduce or stop illumination of bridges during salmon migration or mating period. Any lighting strategy for architecture and urban design should also carefully consider its interaction with other surrounding architectural or natural features (Figure 5).

There is still time to work on the discussed initiative to improve future outcomes. Ideally, this will involve applying best lighting practices as well as long-term consultations with lighting professionals. Many cities and communities around the world are looking for examples of excellence and seeking out forerunners of innovation to follow. This is London's opportunity to lead the way and inspire better design.

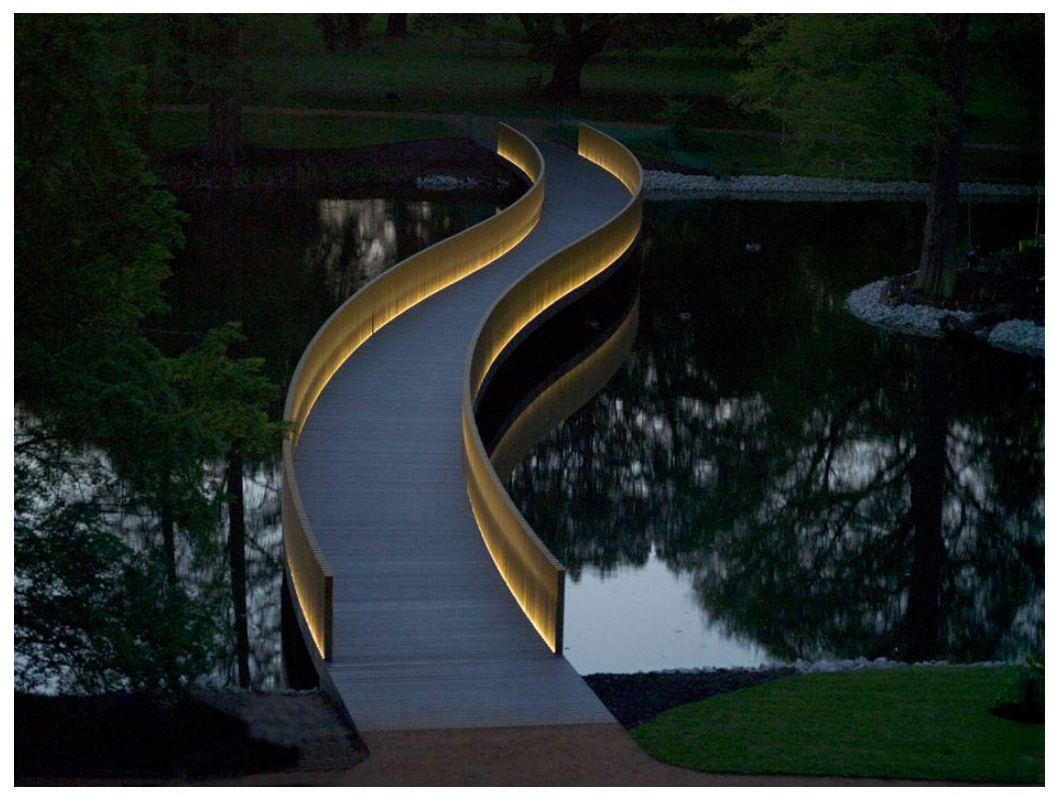

Fig.5. The Sackler Bridge in the Royal Botanic Gardens at Kew, London. An excellent example of sensitive nighttime illumination that complements the architectural design and the natural setting, while providing enough light for users to be able to cross the bridge. (c) James Newton Photography. 
Future decision making. An opportunity to lead the way.

This paper has particular relevance for informing future decisions about appropriate strategies for built environments at night, and addresses the obvious lack of responsible nighttime illumination. This is a complex and vast subject deserving serious attention and focus as the widespread, long-term benefits of appropriate, effective, high-benefit lighting are immeasurable. Indeed, for any city of the future to be prosperous, innovative, and sustainable - responsible illumination for human beings, flora and fauna is paramount.

Municipalities need to work with independent lighting designers who are knowledgeable in urban design and the way in which cities operate and are used. This involves sustainability, light pollution, lighting technology, human health and well-being, environmental effects, energy codes, legislation, and zoning codes etc. Professional consultants should also understand the benefits of preserving darkness, as well as the reintroduction of darkness whilst providing safety, security, and accessibility, incorporating nightlife and considering too, the needs of 24-hour societies.

A blueprint in the form of an Urban Lighting Masterplan (ULM)29 is an absolute necessity for cities and towns. High level guidelines are crucial to address the aforementioned issues as well as integrate all aspects of temporary and permanent illumination. Quite simply, this means the right light, at the right place, at the right time.

\section{References}

1 Gaston, K. J., Visser, M. E., Hölker, F. (2015). The biological impacts of artificial light at night: the research challenge. Phil. Trans. R. Soc. B370: 20140133. [doi> 10.1098/rstb.2014.0133]

2 Cho, Y., Ryu, S.-H., Lee, B. R., Kim, K. H., Lee, E., \& Choi, J. (2015). Effects of artificial light at night on human health: A literature review of observational and experimental studies applied to exposure assessment. Chronobiology International, 32(9), 1294-1310. 3 Falchi, F., Cinzano, P., Elvidge, C., Keith, D., \& Haim, A. (2011). Limiting the impact of light pollution on human health, environment and stellar visibility. Journal of Environmental Management, 92, 2714-2722.

4 Retrieved from http://www.who.int/campaigns/world-health-day/2018/en/ [17.08.2018]

5 Retrieved from http://www.unenvironment.org/ [17.08.2018]

6 Tolman, E.C. (1948). Cognitive maps in rats and men. Psychological Review, Vol 55(4), pp.189-208.

7 Lynch K. (1960). The image of the city. Cambridge MA: MIT Press.

8 Ibid 7, p.1.

9 The Editors of Encyclopaedia Britannica. (2017, November 15). Cognition. In Encyclopædia Britannica. Retrieved from

https://www.britannica.com/topic/cognition-thought-process [26.09.2018].

10 Major, M. The qualities of the Night- Why we need light after dark. P.11 [in]

Zielinska-Dabkowska, K.M., Rohde, M.F. (Eds.) (2017). New Perspectives on the Future of Healthy Light and Lighting in Daily Life. Wismar: callidus. Verlag wissenschaftlicher Publikationen.

11 Boyce, P.R. (2014). Human Factors in Lighting, 3rd edition, Boca Raton: CRP Press,

Taylor and Francis Group, p. 553

12 American Academy of Ophthalmology. Dark Adaptation. Retrieved from

https://www.aao.org/bcscsnippetdetail.aspx?id=a6edf361-aca4-4ad8-8a80-d7ffed8457e1[ 26.09.2018]

13 Harwood R.H. (2001, November 30). Visual problems and falls. Age and Ageing. Suppl 4:13-8.

14 Chartered Institution of Building Services Engineers (CIBSE). (1995). Lighting the Environment. A guide to a good urbanlightingm London, UK.: CIBSE, p. 24.

15 Tcheang $L$, Bülthoff $H H$, Burgess N (2011) Visual influence on path integration in darkness indicates a multimodal representation of large-scale space. Proc Natl Acad Sci USA 108: 1152-1157.

16 Chepesiuk, R. (2009). Missing the dark: Health effects of light pollution. Environmental Health Perspectives, 117(1), 20-27.

17 The Nobel Assembly at Karolinska Institutet. (2017, October 2). The 2017 Nobel Prize in Physiology or Medicine [Press release]. Retrieved from https://www.nobelprize.org/ prizes/medicine/2017/press-release/ [26.09.2018]. 
18 Zielinska-Dabkowska K.M. (2018). Make lighting healthier. Nature 553 (7688) pp. 274-276 [doi>10.1038/d41586-018-00568-7]

19 Rich, C., Longcore, T. (Eds.). (2005). Ecological consequences of artificial night lighting.

Washington,DC: Island Press.

20 Zielinska - Dabkowska K.M. (2013).To light or not to light: Exterior illumination of tall buildings and bridges and its negative impact on the life of birds and fish - what professional lighting designers need to know, Professional Lighting Design (PLD) Magazine, no. 91, pp. 38-43.

21 Atkins, S., Husain, S. and Storey, A. (1991). The influence of street lighting on crime and fear of crime. London: Home Office, Crime Prevention Unit

22 Gaston, K., Davies, T., Bennie, J., \& Hopkins, J. (2012). Reducing the ecological

consequences of nighttime light pollution: Options and developments. Journal of Applied Ecology, 49, 1256-1266.

23 Starlight Initiative (2007). Declaration in defence of the night sky and the right to starlight. La Palma Biosphere Reserve. Retrieved from

https://fundacionstarlight.org/en/cmsAdmin/uploads/o_1cgtpqd8o17h1j0u1q6tgrj 1fv4c.pdf

[26.09.2018].

24 Retrieved from https://www.london.gov.uk/what-we-do/planning/london-plan/new-london-plan [26.09.2018].

25 Retrieved from https://illuminatedriver.london/ [17.08.2018]

26 Retrieved from

https://www.london.gov.uk/what-we-do/planning/london-plan/new-london-plan/download-draft-lon don-plan [26.09.2018].

27 Retrieved from

https://www.london.gov.uk/sites/default/files/draft_london_plan_showing_minor_suggested_chan ges_july_2018.pdf [26.09.2018]

28 Levine, J.S., MacNichol, Jr E.F. (1982). Color vision in fish. Scientific American, 216, pp.108-117.

29 Zielinska-Dabkowska K.M. (Forthcoming 2018). Urban lighting masterplan - origins definitions, methodologies, collaboration and case study [in] Urban Lighting for People: Evidence-Based Lighting Design for the Built Environment, Davoudian, N.(Ed.), London: RIBA Publishing.

https://ribabookshops.com/item/urban-lighting-for-people-evidence-based-lighting-design-for-thebuilt-environment/40315/ 